\title{
Understanding the repercussions of intercultural communicative competence: a study on the degree of students' cultural awareness, social and communication skills ${ }^{1}$
}

\author{
Malissa Maria Mahmud ${ }^{2}$ \\ Shiau Foong Wong ${ }^{3}$
}

\begin{abstract}
Demographic change is transforming the way we communicate. In many parts of the world, the society has become increasingly multicultural and multi-ethnic. In this context, intercultural cognizance is one of the pivotal facets for intercultural communication. The recent years has seen the emergence of the intercultural communicative competence (ICC) concept permeating the education field thereby a large and growing body of literature has commenced to investigate the concept of intercultural communicative competence (ICC) and its repercussion in the context of teaching and learning. The notion of ICC is incepted on the acquisition of several "savoirs" associated with attitudes and values, knowledge, skills of interpreting and relating, skills of discovery and interaction and critical cultural awareness. However, the process of acquiring and negotiating meaning in the context of intercultural communication lies a tremendous challenge and demands a continuous effort. Thus, the objective of this study is to probe on how students' attitudes towards another culture affect their degree of cultural awareness and to deliberate how social and communication skills can foster intercultural competence that is influenced by the level of ICC acquisition. The findings indicate that the students possess intercultural competence in which they demonstrate positive attitudes towards individuals from other cultures; henceforth is reflected in the high cultural awareness amongst the students. Apart from this, the findings yielded also show that the students are able to exhibit and display significant competencies in both social and communication skills which are allied to the high level of ICC acquisition.
\end{abstract}

Keywords: Intercultural communicative competence (ICC); teaching and learning; saviors; cultural awareness; attitudes; social and communication skills.

\section{Introduction}

Possessing intercultural communication skills is one of the vital requirements for any individuals since the world has become smaller due to globalisation. The education industry has seen an increase number of international students seeking opportunities to attain their education in different countries; thus, it creates unique and dynamic manifestation onto how these students adapt and assimilate into the unfamiliar culture which in turns necessitates an adaptive ability or intercultural competence to successfully accustom and acquaint themselves to the new culture. As

\footnotetext{
1 This article presented in International Conference on Education, Psychology, And Social Sciences (ICEPS) 2016, ISSN 2518-2498.

${ }^{2}$ Senior lecturer, Sunway University, Centre of American Education, malissam@sunway.edu.my

${ }^{3}$ Teaching fellow, Sunway University, Centre of American Education, janicew@sunway.edu.my
} 
Mahmud, M. M., \& Wong, S. F. (2016). Understanding the repercussions of intercultural communicative competence: a study on the degree of students' cultural awareness, social and communication skills. Journal of Human Sciences, 13(3), 5561-5573. doi:10.14687/ihs.v13i3.4093

defined by Alfred \& Byram, intercultural competence is defined as the aptitude to adjust, adapt, and alter existing knowledge, attitudes, and behaviours in order to be more flexible towards other cultures which is one of the vital facets for individuals to survive in the globalized world (2002). Byram in 1997 proposed a concept to determine intercultural competence scaffold with five constituent savoirs; attitudes and values, knowledge, skills of interpreting and relating, skills of discovery and interaction and critical cultural awareness (Aguilar, 2010). This concept was studied by numerous researchers which subsequently adds to the myriad of findings in the context of intercultural competence. According to (Perry \& Southwell, 2011), the increase of cultural competence leads to the improvement of attitude such as being respectful as well as an increase in the understanding and relating skills. Moreover, ICC develops cognitive skills by making individuals to be more critical when dealing with different beliefs or cultures (Yershova, 2000). In the aspect of behaviour, it makes an individual to be more open, curious, and possess an upsurge of respect towards other cultures (Deardorff, 2006). This finding resonated with what was discovered by Karnyshev (2014) that activities which integrate the concept of ICC build up tolerance and development of the participants to become active builders in an intercultural environment. Abundant of researches have colligated and established the importance of understanding the significant impacts of intercultural competence; however, only a few have probed into the degree of cultural awareness, social and communication, influenced and linked by the level of ICC acquisition. Thus, the objective of this study is to probe on how students' attitude towards another culture affect their degree of cultural awareness and to deliberate how social and communication skills can foster intercultural competence in which is influenced by the level of ICC acquisition. With the acquired findings from this study, better understanding on how the notion and concept of intercultural competence can be integrated and embedded in the context of teaching and learning for example, collaborative cultural tasks and activities that promote intercultural communicative competence to denote best practices.

\section{Literature Review}

\subsection{The Concept of Intercultural Competence}

The concept of Byram's ICC model has been strongly linked to individuals' self-development and intercultural communication. The definition of intercultural communicative competence has been stated to be complex (Moeller, 2014). Kitsantas (2014) found that students who studied abroad, have different perspectives which influence their communicative behaviour. Thus, making the students to be more open minded than students who have been not exposed to different intercultural surroundings. There are five savoirs in this model and according to Byram's (1997) model, each savoir plays an important role to develop one's intercultural competence. 
Mahmud, M. M., \& Wong, S. F. (2016). Understanding the repercussions of intercultural communicative competence: a study on the degree of students' cultural awareness, social and communication skills. Journal of Human Sciences, 13(3), 5561-5573. doi:10.14687/ihs.v13i3.4093

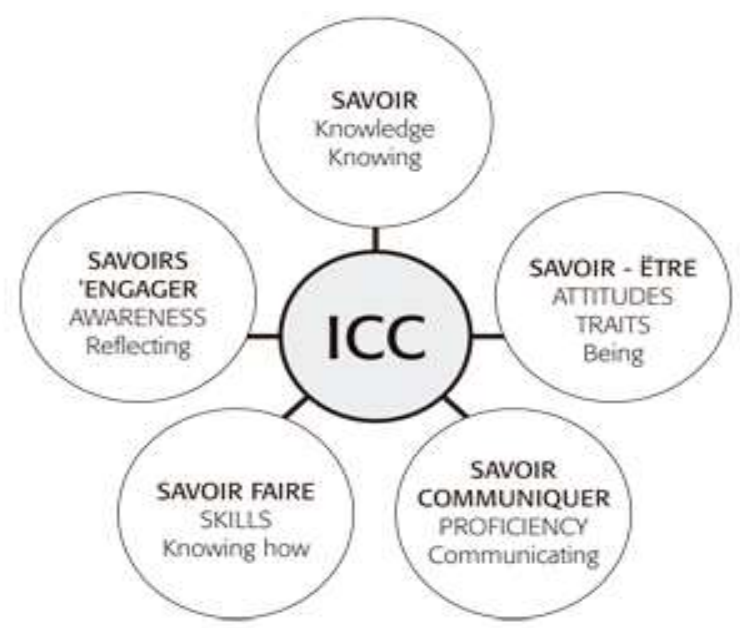

Figure 1: ICC Savoirs by Byram (1997)

Figure 1 illustrates the ICC model by Byram (1997). The model comprises of five savoirs; attitudes and values, knowledge, skills of interpreting and relating, skills of discovery and interaction and critical cultural awareness (Aguilar, 2010). The knowledge savoir propounds the concept of acquiring information regarding to self and others which is the ability to understand their own background and others from other cultures. Interpreting/ relating skills is the ability to interpret and relate to discourses, events, or documents from other culture. Discovery/interaction skill is the ability to obtain new knowledge about other cultures as well as the ability to interact well within different cultures. Attitude is how an individual reacts to intercultural surroundings. How curious and open an individual is to welcome or learn a new culture. Critical intercultural awareness is the skill to evaluate critically on the explicit criteria for instance, perspective, practices, and beliefs in one's own and other cultures or countries.

\subsection{Intercultural Awareness and Attitudes}

The key steps to developing the skills in intercultural communication competence is to have an attitude of self-awareness; to understand and critically analyse one's culture without being judgmental which would eventually lead to building relationships with other cultures (Gudykunst,1993). In the context of teaching and learning, self-awareness enables students to be more humble, understanding, and respectful towards others, thus contributes to an increase in willingness to learn about other students from different cultures. The intercultural communicators archetypally demonstrate a "readiness to suspend disbelief and judgment with respect to others' meanings, beliefs and behaviours" and a "willingness to suspend belief in one's own meanings and behaviours, and to analyse them from the viewpoint of the others with whom one is engaging" (Byram, 1997, p. 34). At this juncture, the ability to disengage or disassociate from the status quo in order to be impartial and empathetic could in a way contribute to having positive perceptions and attitudes towards different cultures. Hence, making the communicators to be more open-minded and knowledgeable (Deardorff, 2006). In addition, it would create mutual respects and understandings towards different cultures and upsurges confidence (Cooper, 2014), and sense of responsibility among students (Karnyshev, 2014).

To achieve intercultural competence, Byram (1997) postulated that communicators have to be competent in each savoir stated in the ICC model. Similar notion was corroborated by Deardorff (2006) that obtaining and demonstrating all repertoires in all the savoirs can aid in attaining the targeted attitude as well as development of one's intercultural competence. Furthermore, it is 
Mahmud, M. M., \& Wong, S. F. (2016). Understanding the repercussions of intercultural communicative competence: a study on the degree of students' cultural awareness, social and communication skills. Journal of Human Sciences, 13(3), 5561-5573. doi:10.14687/ihs.v13i3.4093

important to acknowledge that the mechanisms of attitude are deemed as one of the prevailing factor to elucidate intercultural learning outcomes amongst the students because existing researches indicate that there is correlational element between attitudes and culture. In this instance, Byram (1997) argues that positive attitudes are prerequisite to developing the skills to relate, discover, interpret, and negotiate the differences between varying cultures. Thus, negotiation of meaning necessitates adjustment of own attitudes and perception when approaching different cultures.

\subsection{Intercultural Awareness, Social, and Communication Skills}

Recruiting international students is one of the vital aims for numerous universities where it indicates diversity not only in terms of research and teaching but also, less overtly, a good financial investment for advanced growth (Wright, 2013). In Malaysia alone, the student populations in universities are increasingly multicultural. After graduation, a significantly large amount of today's students tends to work in international organizations. Thus, the ability to work effectively in culturally heterogeneous groups should be an integral part of a student's competence (Popov, Brinkman, Biemans, Mulder, Kuznetsov, \& Noroozi, 2012). Moreover, Escudeiro (2013) believes that in such an ambitious and culturally diverse environment as the labour market is today, it is crucial to promote communication skills at an intercultural level.

Wilson (2011) demonstrated that in order for an international student to be successful, they must adapt socially and culturally to their host country and their new scholarly settings. Wilson (2011) also added that the better the understanding of the host country language, the easier the sociocultural adaptation process. In a number of studies international students found language proficiency to be the most problematic aspect of academic learning (Sawir, Marginson, ForbesMewett, Nyland, \& Ramia, 2012). This finding is corroborated by Zhang (2013), in which international students had to pretend to understand the conversational connotations exchanged with native English speakers due to their limited language proficiency, thus addressing that international students must be able to meet the specific mandatory requirements in academic and language aspects before enrolling in college. In some researches - like the ones from Australia, United States and United Kingdom, two of the most frequently alleged language-related learning problems are oral comprehension and communication. It was noted that a low level of languagerelated proficiencies inflicts time pressures; lectures are recorded and replayed, and discussions in English are slowed by cerebral interpretations. The consistency of the research findings proves that incompetent language proficiency inhibits students outside of the classroom, notably where intercultural communication is required.

Based on Mak's (2013) research on intercultural communication, it was mentioned that linguistic and cultural variety in the aspect of social communications between local and international students has become a prominent element in the leading receiving countries of international students. She further backed the statement by stating that the occurrence of positive communication between domestic and international students has been shown to have constructive consequences for the educational and psychological results of international students from culturally diverse backgrounds. Apart from that, interactions with local students have enabled international students to learn and gain a more in-depth understanding of "the unwritten codes of the local culture" (Montgomery, 2013). This statement is based on a research finding conducted at a Midwestern U.S. public university where peer-pairing programs were organized to match international students with domestic students for substantial interaction outside the classroom. However, one finding by Nittaya Campbell from the Journal of Studies in International Education in 2011 explained that international students have perceived cultural differences, lack of common interests, and the different priorities to be factors that inhibit intercultural communication. Therefore, numerous 
Mahmud, M. M., \& Wong, S. F. (2016). Understanding the repercussions of intercultural communicative competence: a study on the degree of students' cultural awareness, social and communication skills. Journal of Human Sciences, 13(3), 5561-5573. doi:10.14687/ihs.v13i3.4093

researchers have suggested that intervention programs such as focus groups and immersion programs to bridge the cultural gaps as well as to foster connection between the two groups of students would concede tremendous benefits to the students. Based on the discussed literature, it can be deduced that intercultural awareness can lead to a better social and communication skills.

\section{Research Methodology}

A survey was administered to thirty-eight students. The participants were chosen from Sunway University's American Degree Transfer Program (ADTP) due to the rich elements of cultural diversity due to the number of international students in the program and a large majority of students in this program aims to further their studies in the United States and other countries. Hence, the context of the study was deemed apt when probing the existing perceived cultural awareness, attitude as well as social and communication skills amongst the students. The survey consisted of 25 Likert-scale statements; a scale of 1-5 in the order of strongly disagree, disagree, neutral, agree, and strongly agree respectively that had been adapted from Byram's (1997) ICC model. The statistical results obtained from the statements which had been derived from the adapted savoirs would aid in evaluating and appraising the level of intercultural competence professed by the participants. Henceforth, the researchers recommended that higher percentages of either 'Strongly Agree or Agree' indicate significant level of the intercultural competence which is further elaborated in the data analysis section. Below are the statements utilised in the survey:

\section{Knowledge}

a. I learnt brief history about my foreign colleagues' country

b. I got to understand types of causes of misunderstanding between speakers of different cultural origin (such as concepts, gestures, customs and rituals)

c. I know major religions in my foreign colleagues' country

d. I got to know basic knowledge of my foreign colleagues' culture's custom

e. I know the nation's popular geographical information (significant or historical landmarks)

\section{Interpreting/Relating Skills}

a. I am able to recognize the misunderstanding/ misconception of the culture

b. I am able to explain conflicting issues about foreign colleagues' country or culture

c. I am able to interpret event from another culture

d. I am able to compare and contrast other culture to ones

e. I am able to soothe between conflicting interpretations of reality

\section{Discovery/Interaction Skills}

a. I am able to listen to foreign colleagues' conversation

b. I can acquire new knowledge of the culture and foreign colleagues' practices

c. I am able to understand both contemporary and historical events.

d. I am able to appreciate the negotiation of cultural identity in the process of communicating

e. I am aware that every individual has the right to speak out and defend themselves

\section{Attitudes}

a. I am open and willing to learn and understand about different cultures

b. I am able to show positive attitudes when facing different custom 
Mahmud, M. M., \& Wong, S. F. (2016). Understanding the repercussions of intercultural communicative competence: a study on the degree of students' cultural awareness, social and communication skills. Journal of Human Sciences, 13(3), 5561-5573. doi:10.14687/ihs.v13i3.4093

c. I make effort to remind myself that every individual have emotions, experience which influence their reaction

d. I am willing to question and compare the differences between our selected culture and our own

e. I am able to adapt to the way another culture behaves and interact with foreign colleagues' social circles in a way that is appropriate for an outsider.

\section{Critical Cultural Awareness}

a. I am able to recognize significant values and knowledge about the culture's background

b. I am able to respect foreign colleague's values, beliefs, traditions etc. Even when it may clash with our own perspective

c. I am able to identify the differences between contemporary and historical events and issues

d. I have experienced something that made me consider my own culture and values

e. I am able to evaluate critically on the basis of explicit criteria perspective and practices

\section{Results}

\subsection{Demographic}

\begin{tabular}{ccc} 
Nationality & Number & Percentage \\
\hline Malaysia & 28 & $73.7 \%$ \\
China & 1 & $2.6 \%$ \\
Indonesia & 1 & $2.6 \%$ \\
America & 1 & $2.6 \%$ \\
Thai & 1 & $2.6 \%$ \\
Nigeria & 1 & $2.6 \%$ \\
Pakistan & 1 & $2.6 \%$ \\
Others & 4 & $10.5 \%$ \\
Total & 38 & \\
\hline
\end{tabular}

Table 1: Participants' Nationality

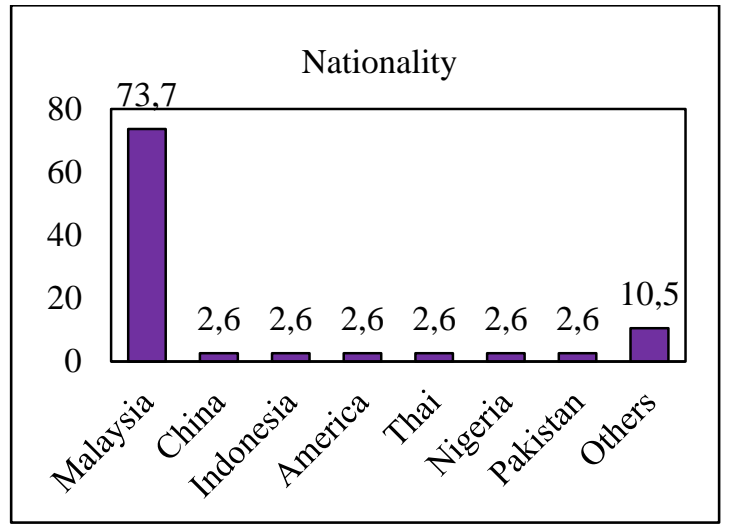

Figure 2: Nationality Distribution

Table 1 shows the distribution of the nationality of the participants. Majority of the participants; $73.7 \%$ is from Malaysia. While the remaining of the participants; $26.3 \%$ are from other countries for example, China, Nigeria, Pakistan, and America just to name a few.

\subsection{Data Analysis}

In order to measure the level of intercultural competence possessed by the participants, the total numbers for the Likert-scale employed in the survey for both 'Strongly Agree or Agree' scales and 'Strongly Disagree or Disagree' scales were combined as the sum generated from either 'Strongly Agree or Agree' scales connote similar interpretation and inference. 
Mahmud, M. M., \& Wong, S. F. (2016). Understanding the repercussions of intercultural communicative competence: a study on the degree of students' cultural awareness, social and communication skills. Journal of Human Sciences, 13(3), 5561-5573. doi:10.14687/ihs.v13i3.4093

\begin{tabular}{ccc} 
Survey Code & Likert Scale & Intercultural Competence Equivalence \\
\hline SD & Strongly Disagree & Student possesses no ICC. \\
D & Disagree & Student possesses a low level of ICC. \\
N & Neutral & Student possesses an average level of ICC. \\
A & Agree & Student possesses a good level of ICC. \\
SA & Strongly Agree & Student possesses an excellent level of ICC.
\end{tabular}

\begin{tabular}{|c|c|c|c|}
\hline Knowledge Savoir & $\mathbf{A}$ & $\mathbf{N}$ & D \\
\hline Statement 1 & 19 & 14 & 5 \\
\hline Statement 2 & 22 & 10 & 6 \\
\hline Statement 3 & 24 & 4 & 10 \\
\hline Statement 4 & 23 & 11 & 4 \\
\hline Statement 5 & 21 & 13 & 4 \\
\hline Total & 109 & 52 & 29 \\
\hline
\end{tabular}

Table 2: Number of Statements for Knowledge Savoir

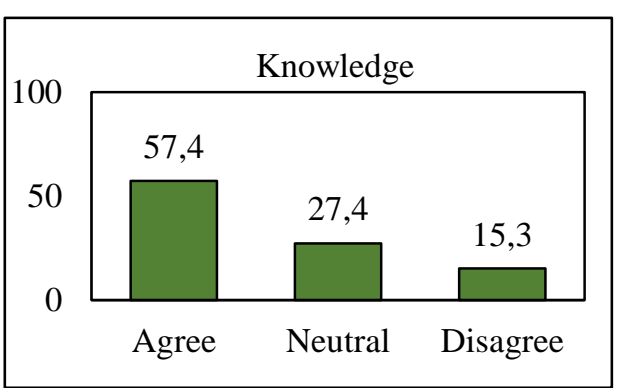

Figure 3: Percentages for Knowledge Distribution

Notation: A - Agree, N - Neutral, D - Disagree

Table 2 shows the number of agreement and disagreement yielded for each statement in the Knowledge Savoir. The agreement scale obtained $57.4 \%$ and the disagreement percentage yielded a mere $15.3 \%$.

\begin{tabular}{|c|c|c|c|}
\hline $\begin{array}{l}\text { Interpreting/Relating } \\
\text { Skills Savoir }\end{array}$ & $\mathbf{A}$ & $\mathbf{N}$ & D \\
\hline Statement 6 & 16 & 16 & 6 \\
\hline Statement 7 & 15 & 14 & 9 \\
\hline Statement 8 & 21 & 10 & 7 \\
\hline Statement 9 & 29 & 5 & 4 \\
\hline Statement 10 & 17 & 16 & 5 \\
\hline Total & 98 & 61 & 31 \\
\hline
\end{tabular}

Table 3 Number of Statement for Relating Skills Savoir

Notation: A - Agree, N - Neutral, D Disagree

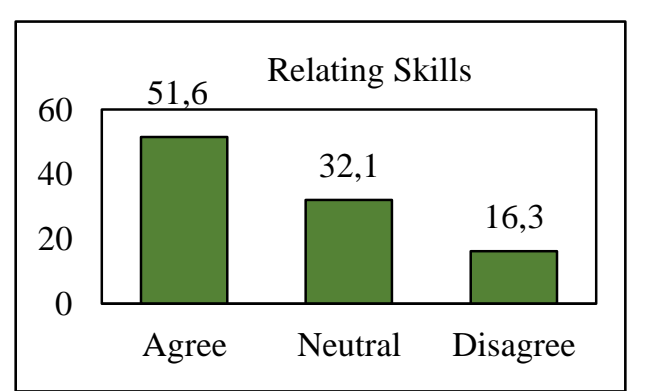

Figure 4: Percentages for Relating Skills Distribution

Table 3 shows the numbers of agreement, neutral and, disagreement generated for each statement in the Interpreting/ Relating Skills Savoir. A significant number of participants with 98 counts $(51.6 \%)$ of agreement were yielded while the disagreement counted a paltry of only 31 counts $(16.3 \%)$. 
Mahmud, M. M., \& Wong, S. F. (2016). Understanding the repercussions of intercultural communicative competence: a study on the degree of students' cultural awareness, social and communication skills. Journal of Human Sciences, 13(3), 5561-5573. doi:10.14687/jhs.v13i3.4093

\section{Discovery/Interaction}

\begin{tabular}{|c|c|c|c|}
\hline $\begin{array}{c}\text { D1scovery/Interaction } \\
\text { Skills Savoir }\end{array}$ & $\mathbf{A}$ & $\mathbf{N}$ & D \\
\hline Statement 11 & 17 & 11 & 10 \\
\hline Statement 12 & 24 & 11 & 3 \\
\hline Statement 13 & 21 & 14 & 3 \\
\hline Statement 14 & 26 & 10 & 2 \\
\hline Statement 15 & 33 & 2 & 3 \\
\hline Total & 121 & 48 & 21 \\
\hline
\end{tabular}

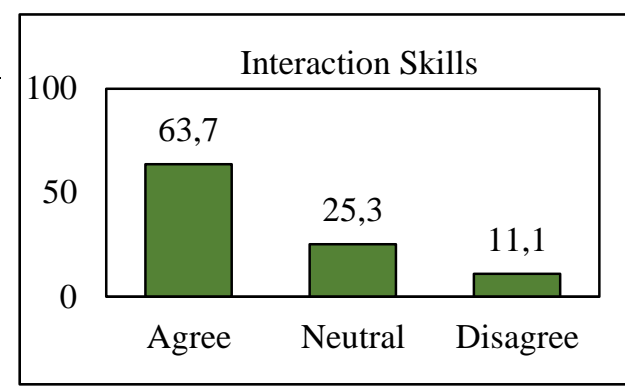

Table 4 Number of Statements for Interaction Skills Savoir
Notation: A - Agree, N - Neutral, D -
Disagree

Figure 5: Percentages for Interaction Skills

Distribution

Table 4 indicates the number of agreement, neutral and, disagreement in the savoir of Interaction Skills. A percentage $63.7 \%$ for the agreement scale was acquired while for the disagreement scale, $11.1 \%$ was generated.

\begin{tabular}{|c|c|c|c|}
\hline Attitudes Savoir & A & $\mathbf{N}$ & D \\
\hline Statement 16 & 34 & 0 & 4 \\
\hline Statement 17 & 34 & 2 & 2 \\
\hline Statement 18 & 33 & 2 & 3 \\
\hline Statement 19 & 28 & 7 & 3 \\
\hline Statement 20 & 26 & 6 & 6 \\
\hline Total & 155 & 17 & 18 \\
\hline
\end{tabular}

Table 5 Number of Statement for Attitudes Savoir Notation: A - Agree, N - Neutral, D - Disagree

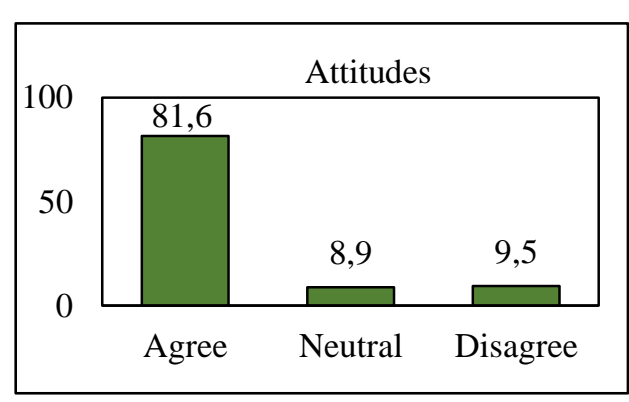

Figure 6: Percentages for Attitudes Distribution

Table 5 shows the number of agreement, neutral and, disagreement in Attitudes Savoir. Majority of the participants $(81.6 \%)$ agreed with the five statements employed in the survey while a slight percentage of the participants $(9.5 \%)$ disagreed with the statements.

\begin{tabular}{|c|c|c|c|}
\hline $\begin{array}{l}\text { Critical Cultural } \\
\text { Awareness Savoir }\end{array}$ & A & $\mathbf{N}$ & D \\
\hline Statement 21 & 28 & 7 & 3 \\
\hline Statement 22 & 29 & 5 & 4 \\
\hline Statement 23 & 22 & 13 & 3 \\
\hline Statement 24 & 29 & 4 & 5 \\
\hline Statement 25 & 28 & 7 & 3 \\
\hline Total & 136 & 36 & 18 \\
\hline
\end{tabular}

Table 6 Number of Statement for Critical Cultural Awareness Savoir

Notation: A - Agree, N - Neutral, D - Disagree

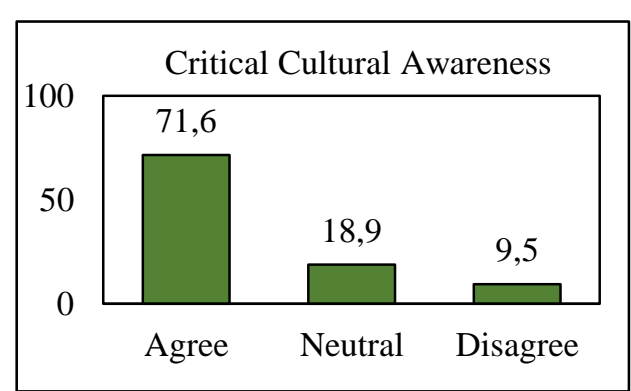

Figure 7: Percentages for Critical Cultural Awareness Distribution 
Mahmud, M. M., \& Wong, S. F. (2016). Understanding the repercussions of intercultural communicative competence: a study on the degree of students' cultural awareness, social and communication skills. Journal of Human Sciences, 13(3), 5561-5573. doi:10.14687/ihs.v13i3.4093

Table 6 shows the number of agreement and disagreement for the Critical Cultural Awareness Savoir. With high agreement produced $(71.6 \%)$ from the statements in the survey, it can be postulated that most of the participants are aware about others' culture. Meanwhile, for the disagreement scale, a percentage of 9.5\% was produced for the Critical Cultural Awareness Savoir.

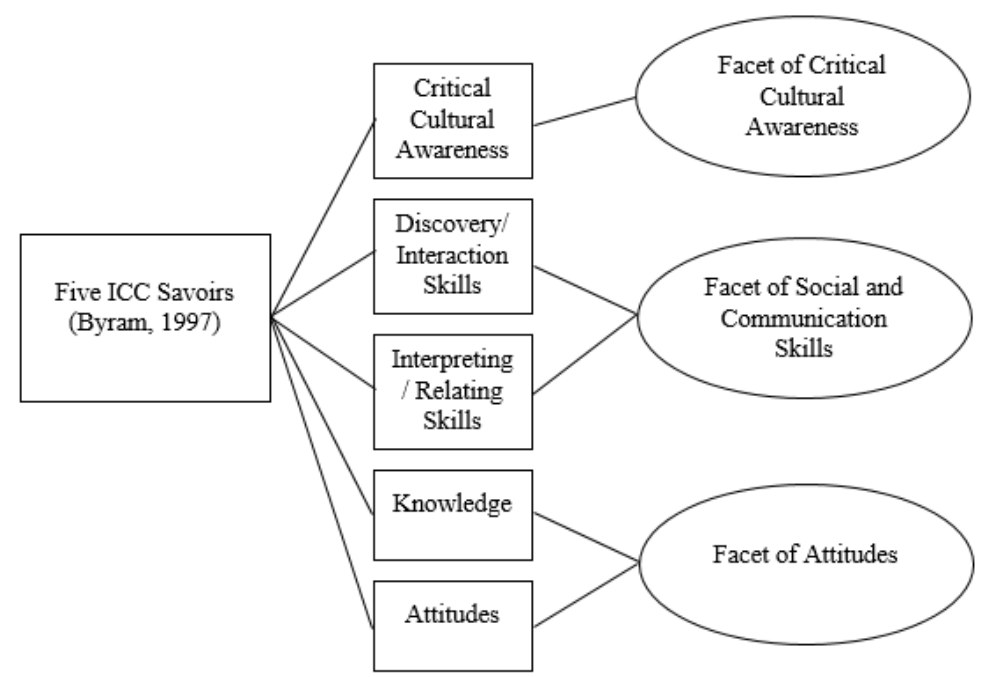

Diagram 1: The Postulated Facets of Critical Cultural Awareness, Attitude, and Social and Communication Skills adapted from Five Intercultural Competence Model by Byram (1997)

It is conjectured that by merging the statistics obtained from Interpreting/ Relating Skills Savoir and, Discovery/ Interaction Skills Savoir to typify the social and communications skills possessed by the participants in this study can assist in providing a magnitude of understanding on how social and communication skills influence intercultural awareness. Moreover, the overlapping notions derived from the statements from both savoirs denote and scaffold the facet of social and communication skills; one of the facets postulated in this study. For instance, the statements employed in the survey specifically for both Interpreting/ Relating Skills Savoir and, Discovery/ Interaction Skills Savoir for example, 'recognizing the misunderstanding', 'comparing and contrasting other culture to ones', 'listening to foreign colleagues' conversation', 'appreciating the negotiation of cultural identity' and etc., were employed essentially to probe on the concepts of which are imperative in acquiring competencies in social and communication skills. Similar method of combination was also employed on both Knowledge and Attitudes Savoirs. In this instance, these two savoirs were synthesized to examine the facet of attitude postulated in this study. It is deemed that the knowledge of others' cultures would influence the attitudes demonstrated; thus, it would be vital to discover the cogent context for both savoirs in a form of a combined statistic which underpins the facet of attitude. Finally, the facet of critical awareness was independently analyzed as it mediates both concepts of attitudes and social and communication skills. The following tables; Table 7 and Table 8 illustrate the combined/ total number of agreement, neutral and disagreement as well as the distributions for the facets of Critical Cultural Awareness, Attitudes and Social and Communication Skills postulated in this study. 
Mahmud, M. M., \& Wong, S. F. (2016). Understanding the repercussions of intercultural communicative competence: a study on the degree of students' cultural awareness, social and communication skills. Journal of Human Sciences, 13(3), 5561-5573. doi:10.14687/jhs.v13i3.4093

\begin{tabular}{lccc} 
& Agree & Neutral & Disagree \\
\hline Critical Cultural Awareness & 136 & 36 & 18 \\
Attitudes & 264 & 69 & 47 \\
Social and Communication Skills & 219 & 109 & 52
\end{tabular}

Table 7: Total Number of Agreement, Neutral, and Disagreement for the Facets of Critical Cultural Awareness, Attitude, and Social and Communication Skills

Table 7 exemplifies the agreement, neutral, and disagreement counts for the facets of Critical Cultural Awareness, Attitude, and Social and Communication Skills. The Critical Cultural Awareness facet obtained 136 counts of agreement meanwhile for the facets of Attitudes and Social and Communication Skills yielded 264 and 219 agreements respectively. In the same vein, the disagreement counts attained were 18 for the Critical Cultural Awareness facet, 47 for the Attitudes facet and 52 for the Social and Communication Skills facet.

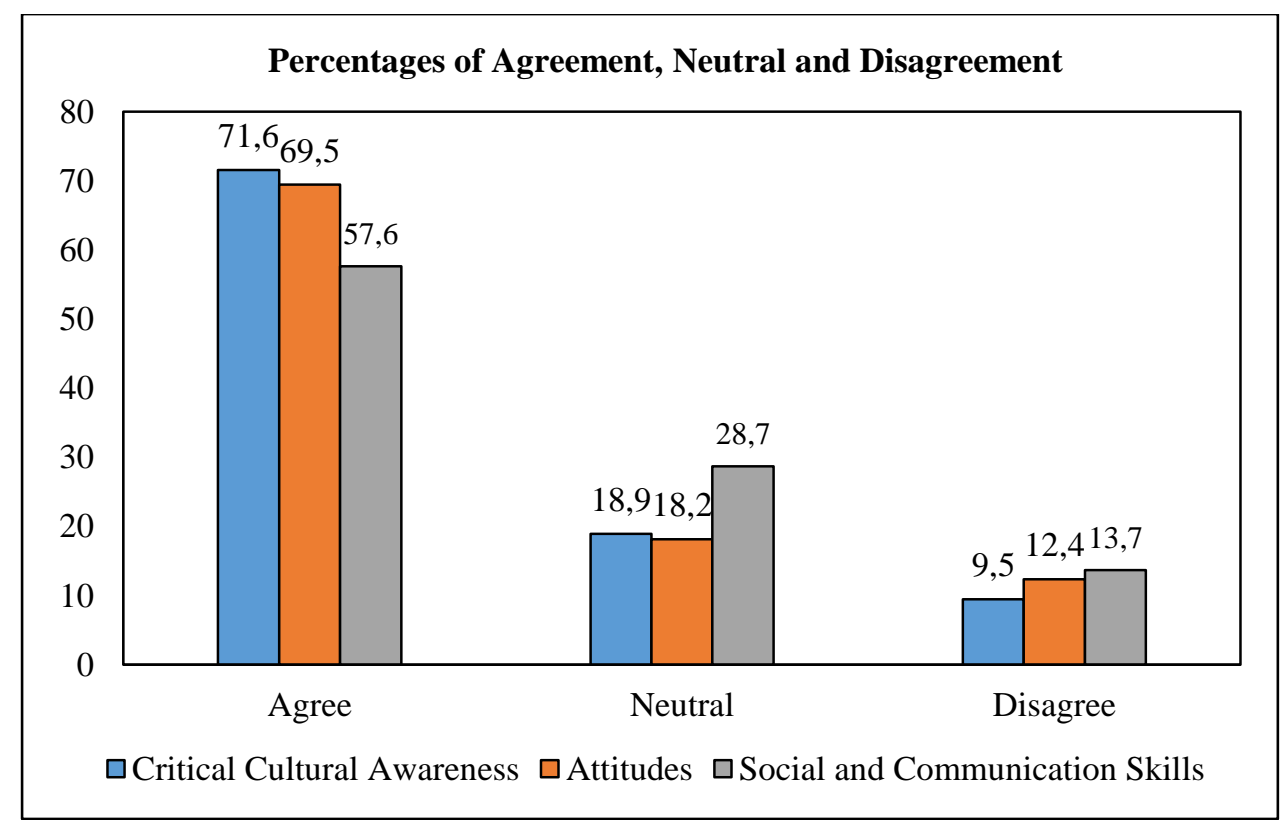

Figure 8: Percentages of Agreement, Neutral, and Disagreement for the facets of Critical Cultural Awareness, Attitude, and Social and Communication Skills

Figure 8 illustrates the percentages of agreement, neutral, and disagreement for the facets of Critical Cultural Awareness, Attitude, and Social and Communication Skills. For the Critical Cultural Awareness Facet, 71.6\% was yielded meanwhile for the Attitudes Facet, 69.5\% was attained, and the Social and Communication Skills Facet produced 57.6\%. In this context, the high percentages obtained for the postulated facets imply that the students possess a significant level of intercultural competence.

\section{Discussion}

The aim of this study is to probe on how students' attitude towards another culture affect their degree of cultural awareness and to cogitate how social and communication skills can foster intercultural competence in which is influenced by the level of ICC acquisition. Consequently, the attained findings from this study would aid in a better understanding on how the notion and concept of intercultural competence can be integrated and embedded in the context of teaching 
Mahmud, M. M., \& Wong, S. F. (2016). Understanding the repercussions of intercultural communicative competence: a study on the degree of students' cultural awareness, social and communication skills. Journal of Human Sciences, 13(3), 5561-5573. doi:10.14687/ihs.v13i3.4093

and learning. As the findings yielded from this study suggest, ADTP students possess a considerable level of intercultural competence in all of the five savoirs adapted from Byram (1997). To further understand the circumstance, three facets; Critical Cultural Awareness, Attitudes and Social and Communication Skills were narrowed down from the adapted five savoirs by Byram (1997). At this juncture, it is deemed essential to narrow down the savoirs to the three abbreviated facets since these facets contribute to an imperative and principal role in developing intercultural competence.

The first facet postulated in this study is the Facet of Critical Cultural Awareness. The statistic revealed that the students indeed possess a substantial grasp and familiarity towards other cultures. This is supported by the attained percentage of $71.6 \%$. The finding does not only suggest the prevalence critical and cultural awareness attributed by the students but also advocate the notion that the students are willing to be empathetic towards other cultures which in turn reinforces the fact that these students are undoubtedly competent interculturally. Moreover, acquiring important knowledge and information on cultural differences is crucial and fundamentally one of the predominant factors that shape individuals to be interculturally competent. Thus, it can be inferred that ADTP students are culturally learned and knowledgeable in the aspect of communicating in the context of different cultures.

As suggested by the findings, the Attitudes Facet generated 69.5\%. In this context, it can be posited that the manifestation of positive attitudes towards individuals from other cultures is prevalent amongst the students. This is perhaps mainly due to the fact that a myriad of cultural revelation is ubiquitous in the setting of this study. The statistics show that the ratio of Malaysia students to foreign students is about 7 to 3 . Thus, indicates that ADTP students who are of mixed background have indirectly contributed to one of the apparent factors that they are more culturally sensitive. Such environment provides opportunity for the students to explore cultural diversity and interact in a culturally sensitive manner; therefore, is promoting their cultural understanding and awareness. This quality makes the students to be more inclined to accept and embrace uniqueness and differences of other cultures as they are confronted with more avenues to understand different cultures from different viewpoints. According to O'Neil (2012), with students of different races and nationality together, they learn more about others through their willingness, openness, and motivation to engage with another culture, even in the face of difficulty. At this juncture, it can be deduced that students who are exposed to more cultures possess better intercultural competence level. Furthermore, intercultural competent individuals are able to display "readiness to suspend disbelief and judgment with respect to others' meanings, beliefs and behaviours" (Byram, 1997). In this context, disassociation from their existing beliefs would lead to being open minded. According to Molinsky (2010), attitudes towards cultural adaptation are developed over time and it is changed and influenced by the environment. Thus, possession towards cultural differences cultivates and inculcates appropriate behaviours to be adapted to the necessitated situation.

Besides the facet of attitudes, another facet probed in this study is the facet of Social and Communication Skills. The findings yielded a significant percentage of agreements (57.6\%); thus, it can be inferred that ADTP students are in fact interculturally competent in which they are able to exhibit the aptitude and skills to communicate and maintain social relationships with others from different cultures. It is palpable for any means of communication to be successful, a mere acquisition of a linguistic code is undoubtedly insufficient; henceforth, the knowledge of basic values and norms ought to be cultivated in the social and communicative processes (Suntharesan, 2013). At this juncture, when cultural norms are learnt and integrated into social and communication processes, willingness to embrace different and unique ideas incepted from different cultures would be much easier. Popov, Brinkman, Biemans, Mulder, Kuznetsov, \& 
Mahmud, M. M., \& Wong, S. F. (2016). Understanding the repercussions of intercultural communicative competence: a study on the degree of students' cultural awareness, social and communication skills. Journal of Human Sciences, 13(3), 5561-5573. doi:10.14687/jhs.v13i3.4093

Noroozi (2012) mentioned that a student's competencies could be judged based on his/her ability to work in culturally heterogeneous groups. With intercultural competence embedded as part of the integral component in the communication processes, the students can acquire new knowledge about different cultures and they would be able to establish relationships with others regardless of their cultures. According to Mak (2013), positive communication between domestic and international students can lead to healthy psychological outcomes. Thus, such ramifications can lead to positive repercussions for the education industry. Finally, it has also been established that it is rather challenging to communicate interculturally (Ke, 2011, \& Neuliep, 2012). Nonetheless, it is a transmission process which entails individuals to invoke motivation to learn about new things though it could be peculiar, be open minded and most importantly to be respectful of others from different cultural background, in order to be able to communicate competently within intercultural environment.

\section{Conclusion}

This study was conducted with the aim to probe on how students' attitudes towards another culture influence the level of cultural awareness as well as to determine how social and communication skills can promote intercultural competence. The findings yielded suggest that intercultural competence environment allows the students to be exposed to varying intercultural surroundings which contribute and influence their attitudes to be more cultural sensitive towards other cultures. With the positive attitudes towards cultural difference, students are able to develop intercultural competence by gaining knowledge about different cultural practices which directly improves their cultural awareness. Furthermore, the results also signify that social and communication skills are crucial in developing intercultural competence. By possessing these skills, the students are able to confidently and actively engage in intercultural communication processes with individuals from culturally diverse backgrounds which would augment their intercultural competence.

\section{Limitation and Future Researches}

A few limitations were faced during our research; the most prominent limitation is time. We were constraint with limited time to collect more data since the survey was distributed during a short semester. Thus, affects the turnaround of the returned surveys. Undoubtedly, the basis of this whole research is to identify the level of intercultural competence amongst ADTP students in Sunway University. However, this research could be broadened towards the whole university. Also, the demographic data collected could be analyzed further to discover if the levels of intercultural competence are influenced by age, gender, nationality, ethnicity, language spoken or amount of countries visited. On top of that, more analysis could be done; specifically, on the responses of students of different nationalities using Kruskal Wallis test of variance, to analyze the responses of the students with gender as the independent variable.

\section{References}

Aguilar, M. J. (2010). Intercultural Communicative Competence as a tool for autonomous learning. Alfred, G. \& Byram, M (2002). Becoming an Intercultural Mediator: A Longitudinal Study of Residence Abroad. Journal of Multilingual and Multicultural Development 23(5), 339-352.

Byram, M. (1997). Teaching and Assessing Intercultural Communicative Competence. Multilingual Matters. 
Mahmud, M. M., \& Wong, S. F. (2016). Understanding the repercussions of intercultural communicative competence: a study on the degree of students' cultural awareness, social and communication skills. Journal of Human Sciences, 13(3), 5561-5573. doi:10.14687/ihs.v13i3.4093

Deardorff, D. K. (2006). Identification and Assessment of Intercultural Competence as a student outcome of Internationalization. Journal of studies in international education.

Escudero, L. M. (2013). Discussing Content and Language in Integrated Learning in Domain Name Dispute Resolution.

Gudykunst, W. B. (1993). Communication in Japan and the United States, State University of New York, Albani.

Karnyshev, A. D., O. A. Karnysheva, and E. A. Ivanova. "College Students' Intercultural Competence And Interethnic Tolerance.” Russian Education \&amp; Society 56.9 (2014): 326. Web.

Karnyshev, A. K. (2014). College Students' Intercultural Competence and Interethnic Tolerance. Russian Education and Society.

Ke, G. (2011). Cultural Difference Effects on Business Holding Up Sino-US. Business Negotiation As a Model. Cross-cultural Communication, 7(2), 101-104.

Kitsantas, A. (2014). Ethnic and Gender Differences in First-year College Students' Goal Orientation, Self Efficacy, and Extrinsic and Intrinsic Motivation. The Journal of Education Research.

Moeller, A. J. (2014). Building Intercultural Competence in the Language Classroom.

Molinsky, A. (2010). A Situational Approach for Assessing and Teaching Acculturation. Journal of Management Education, 34 (5), 723-745.

Montgomery, M. (2013). An introduction to language and society (third version), Routledge, New York, NY.

Neuliep, J. W. (2012). Intercultural Communication: A contextual approach. United States of America.

Nittaya, C. (2011). Promoting Intercultural Contact on Campus: A Project to Connect and Engage International and Host Students. Journal of Studies in International Education.

O'Neill, G. H. (2012). Developing and Evaluating Intercultural Competence: Ethnographies of Intercultural Encounters. International Journal of Intercultural Relations.

Perry, L. B., \& Southwell, L. (2011). Developing Intercultural Understanding and Skills: Models and Approaches. Intercultural Education, 22(6), 453-466.

Popov, V., Brinkman, D., Biemans, J. A., Mulder, Md, Kuznetsov, A., \& Noroozi, O. (2012). Multicultural Student Group Work in Higher Education: An Explorative Case Study On Challenges As Perceived by Students.

Sawir, E., Marginson, S., Forbes-Mewett, H., Nyland, C., \& Ramia, G. (2012) International student security and English Language Proficiency. Journal of Studies in International Education, November 2012, vol. 16 no. 5.

Suntharesan, V. (2013). Importance of Developing Intercultural Communicative Competence among Students of ESL (Special Reference to Jaffna Students). Language in India, 13(2).

Wilson, G. P. (2011). Fitting- in: Sociocultural adaptation of international graduate students. NERA Conference Proceedings 2011.

Wright, C. (2013). 'I can't ... I won't?' International students at the threshold of social interaction. Journal of Research in International Education, August 2013, vol. 12 no. 2.

Yershova, Y. (2000). Thinking not a usual: Adding the Intercultural Perspective. Journal of Studies in International Education.

Zhang, Z. C. (2013). Business English students learning to write for international business: What do international business practitioners have to say about their texts? English for Specific Purposes, 32(3), 144-156. 